\title{
A pandemia COVID-19 no Brasil: ecos e reflexos nas comunidades periféricas
}

Maria Helena Magalhães de Mendonça, Aluisio Gomes da Silva Junior, Carlos Leonardo Figueiredo Cunha, Paula Kwamme Latgé

\section{RESUMO}

Este artigo aborda a questão social das desigualdades socioeconômicas no Brasil e seu impacto na organização das políticas públicas nas grandes cidades que interferem na atuação da Atenção Primária à Saúde (APS) no enfrentamento da COVID-19. Foca nas iniciativas surgidas no âmbito da sociedade e Estado valorizando a solidariedade social, a democracia participativa e as iniciativas comunitárias. Por fim, aponta as lições que a pandemia trouxe para o campo da APS e da Saúde Coletiva.

Palavras-chave: Desigualdade; Políticas Públicas; Saúde Pública; Assistência Social e Participação Social.

\section{ABSTRACT}

This article analyse the social issue of socioeconomic inequalities in Brazil and its impact on the organization of public policies in large cities interfering in the performance of PHC in coping with COVID-19. It describe initiatives that have emerged within society and State valuing social solidarity, participatory democracy and Community initiatives. Finally, it points out the lessons that the epidemic brought to the field of PHC and Public Health.

Keywords: Inequalities; Public Policies; Public Health; Social Assistance and Social Participation.
Revista da Rede APS 2020

Publicada em: 09/06/2020

DOI:10.14295/aps.v2i2.124

Maria Helena Magalhães (Escola Nacional de Saúde Pública, Rio de Janeiro, RJ, Brasil)

Aluisio Gomes da Silva Junior (Universidade Federal Fluminense, Niterói, RJ, Brasil)

Carlos Leonardo F. Cunha (Universidade Federal do Pará, Belém, PA, Brasil)

Paula Kwamme Latgé (Universidade Federal Fluminense, Niterói, RJ, Brasil)

Correspondência para: Maria Helena Magalhães mhelenamendoca16@gmail.co $\underline{m}$

Aluisio Gomes da Silva Junior agsilvaj@gmail.com

Carlos Leonardo F. Cunha leocunhama@gmail.com

Submissão recebida em 26 de maio de 2020 .

Aceito para publicação em 08 de junho de 2020.

Artigo de editor avaliado pelo sistema Double Blind Review.

(c) 


\section{CONTEXTO E PRINCIPAIS QUESTÕES DA}

\section{PANDEMIA QUE IMPACTAM A VIDA}

\section{SOCIAL}

A crise atual do capitalismo que incide diretamente na crise sanitária agravada pela pandemia da COVID-19, exige respostas da esfera política para às ameaças da cidadania, dos processos democráticos e da proteção social, que agravam a recessão e depressão econômicas, o avanço do desemprego e desproteção do trabalho.

Estas respostas tencionam entre a perspectiva liberal que demanda por uma economia capitalista ativa (mesmo que a base da circulação de trabalhadores informais, precários) e a adoção de medidas de proteção social emergencial indutoras de isolamento social e implementação de medidas de distribuição de renda, ampliação do emprego e acesso ao sistema de serviços sociais e de saúde integrais que se opõem a austeridade fiscal.

As dificuldades estruturais da vida coletiva nas grandes cidades fazem com que diversos segmentos busquem alternativas na economia solidária e novas formas de organização social comunitárias e periféricas. Contudo, desde os primeiros momentos da pandemia ensaiava-se um consenso amplo quanto à necessidade de intervenção do Estado para regular as relações sociais e formular políticas sociais, de dimensão pública.

A implementação de medidas sanitárias são fundamentais para exercer autoridade, cuidar e recuperar um conjunto da população de milhares de pessoas, que podem ser afetadas mais drasticamente por esta pandemia de forte corte social, pois atinge diferentemente a população que vive em condições mais precárias e vulneráveis ${ }^{1}$.

São muitas as vozes e mentes a lembrar que as condições sociais e epidemiológicas que induzem a necessidade de isolamento social e sua face real - individual ou coletiva-, serão responsáveis por circunstâncias de grandes desigualdades sociais entre grupos de risco por doenças crônicas, por condições de exclusão e vulnerabilidades (população de rua, carcerária, pobres, pessoas que vivem com HIV, indígenas e quilombolas) e a população em geral ${ }^{1}$.

Nos últimos anos, a assistência a esses diferentes grupos tem sido objeto de políticas especificas, que visam aproximar os serviços de saúde da população respondendo às características e necessidades determinadas e enfatizando as dificuldades de acesso. A estruturação de programas pelas secretarias de saúde de estados e municípios como Consultório na Rua, saúde indígena e de populações remotas aproximaram o SUS dessas populações, buscando conhecer melhor suas demandas no seu território em articulação com os atores do nível local. Esses grupos vivem cotidianamente situações de isolamento, que agora podem se agravar caso não haja uma consistente prevenção da COVID-19.

$\mathrm{Na}$ pandemia, cuidar das populações em situação vulnerável nas grandes cidades é acolhê-las ou ofertar serviços sociassistenciais público ou privado de acordo com o marco legal de acolhimento institucional ${ }^{2}$, ou tornar a rua menos nociva para quem nela permanecer em consequência da desigualdade socioeconômica brasileira. Os serviços públicos do SUS devem acolhê-las, sem restrições em relação ao seu modo de vida, em ação articulada entre diversos atores do Estado (da saúde, da saúde mental, da assistência social, alimentação, trabalho, etc.) e as iniciativas da sociedade civil. Portanto as ações públicas tendem a ser intersetoriais e interinstitucionais com base em informações seguras da dimensão dessa população, suas comorbidades, etc. que podem ser agravadas no contexto da pandemia.

Historicamente, as análises de saúde pública nos mostram a importância de eventos emergenciais para construir respostas públicas de largo alcance que reflitam o presente e projetem o futuro. As medidas sanitárias neste contexto quando se voltam a população em geral $\mathrm{e}$ as que vivem em condições mais 
precárias e vulneráveis nas favelas, bairros populares, constituindo-se em grupos de risco por doenças crônicas e por condições de exclusão social (população de rua, carcerária, pobres, pessoas que vivem com HIV, indígenas e quilombolas), devem se apoiar em mapeamentos dos grupos que orientem a atuação do Estado em conformidade com o conhecimento por eles produzidos em seu território, dando suporte ao acompanhamento, prevenção, assistência e recuperação dos doentes com acesso a atenção primária no SUS.

Essa pressão sobre os sistemas e serviços de saúde por recursos e acesso requer maior dotação orçamentária, na contramão da política austera adotada nos últimos anos que amplia a exclusão social e informalidade nas relações trabalhistas. $O$ desafio agora é romper entraves, recuperar políticas sociais e resguardar o conceito de seguridade social mais abrangente contido na Constituição de 1988 para o exercício da cidadania e da democracia ${ }^{3}$, efeito de muitas tensões e disputas na esfera pública.

Se falta uma ação estatal estruturada e coordenada em plano emergencial de assistência para toda população e recuperação da sociedade/economia pós pandemia, vê-se com esperança movimentos sociais baseados em cooperação social e solidariedade no enfrentamento da crise sanitária por iniciativas da sociedade civil organizadas em coletivos em alianças com instituições e governos locais que se voltam ao bem estar da sociedade.

\section{AS EXPERIÊNCIAS COMUNITÁRIAS SOBRE}

\section{A PANDEMIA E SUAS CIRCUNSTÂNCIAS}

A primeira medida de restrição dos governos em 16 de março, adotada pelos estados diante dos primeiros casos infectados e suspeitos, deu início a quarentena com restrição de transportes coletivos, fechamento de escolas e pequenos comércios para redução da circulação. O centro do debate comunitário pelo isolamento social foi a condição de adesão à privação de liberdade quanto à defesa da mobilidade e sustentabilidade, exiguidade das recomendações de isolamento e higiene pessoal e o uso de máscara.

A perspectiva solidária de não se expor por si e por todos esbarrou na influência negativa do discurso presidencial, interrompendo ou retardando o isolamento, criando conflitos entre entes governamentais e segmentos sociais e aumentou a violação de direitos humanos de diversos recortes: racial, de gênero, de vulnerabilidade e precariedade econômica e consequente exposição das profundas desigualdades e assimetrias sociais.

Somou-se ainda ao temor da população quanto aos atestados de óbitos não representativos pela falta de testes e tempo de retorno dos resultados de diagnóstico, que afetou a vida das famílias e a decisão política com base em notificação correta da pandemia. Urge preservar a integralidade da atenção pela vigilância em saúde, pelos atributos clínicos e projeções comunitárias da APS para conter a propagação da doença e enfrentar as desigualdades em consonância com as práticas comunitárias.

O acompanhamento de matérias na mídia e nas redes sociais onde ecoavam as vozes de suas lideranças e permitiu elencar diversas ações sociais pela preservação da vida, pela doação de alimentos, produtos de higiene e ainda por meio da comunicação social que informa, educa e protege a saúde. Assim, se inferiu uma antecipação do movimento social em relação ao Estado em muitas comunidades da capital e áreas das regiões metropolitanas especialmente no Rio de Janeiro, mas também em outras regiões do país.

Exemplos como articulações para preservar a renda de produtores de quentinha, que perderam a condição de ganho em diversos bairros da cidade, aproximando-os dos moradores de rua, que por sua vez perderam doações voluntárias. A combinação da ação resultou uma rede de doações, de suporte administrativo e planejamento para a compra 
das quentinhas para a população de rua, grupos vulneráveis e autônomos de uma dada região junto a produtores da mesma região, em que eram distribuída, formando um circuito solidário ${ }^{4}$

A união de campanhas de comunidades de diversos complexos como Maré, Manguinhos e Alemão, Babilônia, Jacarezinho para oferta de fraldas geriátricas, cestas básicas, produtos de limpeza com incentivos a propostas junto a empresas locais, artistas, vaquinhas e ferramentas internáuticas, favoreceram a identificação de famílias suspeitas de contaminação; famílias sem renda, desempregadas e intervenções diferenciadas ${ }^{5}$.

As comunidades abrigam milhares de trabalhadores autônomos, empreendedores vivendo de seu trabalho diário para quem o isolamento representa redução de renda, daí a urgência do auxílio e outras complementações. Atribuem responsabilidade aos políticos e governantes na definição de transferência de renda, assistência social associados a manutenção do afastamento social com o fechamento do comércio e serviços locais bem como a liberação de serviços urbanos necessários - agua, luz, gás ${ }^{6}$.Pauta que reflete um sentido mais amplo de segurança social e planejamento emergencial voltado aos mais vulneráveis ${ }^{7}$.

As lideranças formadas de ACS, educadores populares e agentes sociais diversos, defendem que as favelas sejam olhadas pelo Estado como parceiras nessa pandemia, indicando a força da participação social, forjada na relação recíproca entre Estado e sociedade no local considerandose seus limites e possibilidades ${ }^{8}$. Os movimentos populares são instados a se renovar a cada momento e se organizam em redes sociais e trabalham duro na comunicação social com faixas em favor do isolamento e falam por um coletivo unificado além de se articularem e apoiarem postos de saúde, também abandonados pelo Estado quando mais precisariam ter recursos para responder à crise.
A organização das redes sociais permite a conscientização e disseminação de hábitos de higiene e isolamento, a organização de rede de generosidade com diversas campanhas de arrecadação de bens e recursos para as campanhas de comunicação. A parceria com o poder público potencializa até mesmo as pessoas de risco que estão em casa mas podem atuar pelas suas redes de afeto em prol do isolamento dos doentes; pessoas saudáveis ajudam o mapeamento, moradores divididos em grupos confeccionam faixas, máscaras, distribuem recursos doados, levantam problemas - violência doméstica, acumulo de tarefas dentro da casa.

Uma forte preocupação dessas lideranças em momento tão crítico é não isolar a favela da cidade. A pandemia começou nos bairros nobres que não pensaram em se fechar para não contagiar. As dificuldades das favelas são reais, seus problemas são de classe social. Essas lideranças reclamam da falta de indicadores apropriados para as favelas, considerando sua população e suas condições socioeconômicas6.

Elas também recebem o suporte de atores que defendem os direitos humanos em articulação política com entidades de classe, parlamentares municipais, estaduais e federais organizados em mandato(a)s progressistas que acolhem as demandas em torno de questões emergentes inclusive neste contexto de pandemia como a violência doméstica a mulheres, idosos e crianças, e elaboração de propostas de acolhimento às vítimas em hotéis no Rio de Janeiro, instrumento de afastamento do convívio social de pessoas em risco, que se estende a vulneráveis como população de rua, dependentes químicos e incapacitados, etc ${ }^{9}$.

Estas medidas de abrigo por afastar pessoas em risco do convívio social e familiar devem ser compulsórias na perda temporária de autonomia sem ferir a liberdade individual segundo a Comissão da Defesa dos $\mathrm{DH}$ e da Cidadania da ALERJ que criou um canal específico para troca de mensagens 
denominado Zap da Cidadania específico para denúncias.

Os líderes comunitários e políticos ao fortalecerem as bases populares refletem o receio de um regime de proteção autoritário e negociam no território a superação dessas dificuldades observadas também em outras metrópoles e cidades grandes do interior do país como São Paulo, Porto Alegre, Belém ${ }^{10,11}$. Observaram-se ainda inovações nas ações intersetoriais, nas estratégias de participação social e organização dos coletivos populares em articulação com os serviços de saúde, e avanços na reorganização das estratégias de ações para enfrentamento da pandemia ${ }^{8}$.

A rede de pesquisa APS além de acompanhar na mídia o tema da participação social se aproximou de experiências governamentais e institucionais em Florianópolis, Sobral, Belo Horizonte, Rio de Janeiro/Complexo do Alemão e Niterói e divulgou informações de seus representantes em boletins de notícias da Rede $\mathrm{APS}^{12,13}$. Essa troca entre gestores, profissionais de saúde, lideranças comunitárias e pesquisadores no âmbito de oficinas semanais do Comitê gestor da rede APS em tempos de enfrentamento da pandemia reuniu alternativas de organização da atenção primária à saúde em âmbito municipal ou local e de organização comunitária que potencializam a análise das interfaces estado e sociedade, sendo a atenção primária um lugar estratégico e dialógico para novas formas de organização do cuidado. Essas experiências são moldadas pelo contexto sócio, econômico e cultural de seus territórios, nas suas potencialidades e desafios.

\section{AfINAL QUE LIÇõES A PANDEMIA}

\section{TROUXE AOS TERRITÓRIOS?}

O movimento social nas comunidades hoje presta um cuidado paliativo, e cria expectativa de fortalecimento diante da sociedade e pressão por novas estruturas urbanas mais democráticas, baseadas na realidade das carências sociais, exponenciadas agora pela pandemia. Aposta na unificação de coletivos no âmbito local e se articula através de entidades regionais como a Central Única das Favelas CUFA para ampliar sua organicidade junto às muitas comunidades espalhadas na cidade e no país.

A aposta é no lema Nós por Nós, por um princípio de solidariedade social e pela necessidade de mudança radical de políticas públicas (habitação, saneamento básico, acesso à água, serviços básicos, renda, trabalho, saúde e educação). Preservar a autonomia e alternativas concretas vindas da solidariedade das redes sociais, dos laços familiares e de amizade que circulam em nova dinâmica. Esperam a volta da vida coletiva, sem saber ao certo como ela se fará. Dado a incerteza, Santos alerta aos intelectuais sobriedade e precaução diante das repercussões da pandemia. Hoje, 'a liberdade pode estar na disciplina, na aceitação do distanciamento social e solidário de uns com outros, para chegarmos a um novo limiar de vida social' ${ }^{14}$.

Em face do dilema da pandemia sobre qual dinâmica a sociedade deve adotar os movimentos sociais acatam a recomendação internacional, bem sucedida, baseada em pesquisa histórica, de médio prazo e contrapõese ao aprofundamento da necropolítica de eliminação de grupos mais vulneráveis, pela exposição de jovens e trabalhadores informais. Avançam e inovam em instrumentos participativos como os comitês e escritórios de crise com forte reforço para novas formas de comunicação social e educação popular para mudanças de valores, hábitos e atitudes. Nestas novas formas de participação observam-se a construção de identidades, a existência de sujeitos políticos capazes de intervir na realidade social ${ }^{8}$.

Diante desse cenário de incertezas e sofrimento, a comunicação em saúde pode ocupar um lugar estratégico, caso não fique restrita a transferência de informações prontas, e não dialógicas. Faz-se fundamental que a 
comunicação seja pensada como instrumento de transformação da realidade e não uma técnica de poder, superando a comunicação como lugar de transmissão de regras, como ordenamento de única direção. Partindo desse princípio é que surgiu entre diversos exemplos a experiência dos Jovens Comunicadores em saúde em municípios fluminenses.

A Frente Papagoiaba de promoção dos direitos da juventude negra de Niterói e São Gonçalo, com o suporte da Associação Experimental de Mídia Comunitária - BEM TV e o apoio Instituto de Saúde Coletiva da Universidade Federal Fluminense articula instituições e propõe ação conjunta em parceria com a gestão pública. 0 processo dos Jovens Comunicadores tem como base uma comunicação pautada em produções próprias e adaptações de informações genéricas em conteúdos situados em pessoas e lugares, conversações entre jovens, moradores, atores públicos (profissionais da Atenção Primária e Proteção Social Básica; gestores públicos e profissionais das instituições de ensino) para fortalecimento do acesso aos serviços e benefícios, troca de informação, esclarecimento de dúvidas e acompanhamento das políticas públicas e ações emergenciais apresentadas pelo poder público como resposta a pandemia da COVID-19.

De forma semelhante, os coletivos do Complexo da Maré, especialmente de mulheres, e do Complexo do Alemão com formação diferenciada se apresentam como comunicadores sociais que buscam imprimir conteúdos plausíveis às normativas oficiais sobre a adesão ao isolamento social, além de articulação com os serviços de atenção primária para melhor se apropriar da situação das comunidades e trocar informação sobre e no território. Por sua vez, encontraram nos gestores e coordenadores do cuidado da ESF nestas localidades mediadores abertos a dialogar com as demandas, esclarecer os fatos ocorridos no território e trocar os recursos disponíveis.
Concluindo, as narrativas das experiências de profissionais, lideranças e gestores apresentadas retrataram diferentes formas e presença do Estado e da sociedade na condução de estratégias de ação e controle que, por sua vez, traduzirão distintos resultados para retardar e mesmo retrair a transmissão da doença no território.

Ressalta-se, que apesar das diferentes respostas desencadeadas pelo encontro com a COVID 19, existe por grande parte dos atores envolvidos quase um consenso ao reconhecer que o enfraquecimento da seguridade social, com a reforma da previdência e contínuos cortes orçamentários na saúde e assistência social agravam diretamente os efeitos da pandemia na vida da população, principalmente da população historicamente mais vulnerabilizada. 


\section{NOTAS E REFERÊNCIAS}

1- Barreto et.al - O que é urgente e necessário para subsidiar as políticas de enfrentamento da pandemia de COVID-19 no Brasil? Rio de Janeiro: Revista Brasileira de Epidemiologia, 23: E2000320, 2020.

2- Brasil, MDS/CNAS - Resolução no. 109. Aprova a Tipificação dos serviços Socioassistenciais. Em 11/11/2009, publicada em DOU em 25/11/2009.

3- Mendonca, MHM; Gondim, R.; Matta, G. e Giovanella, L - Os Desafios Urgentes e Atuais da Atenção Primária à saúde no Brasil. In Mendonça, MHM et al - Atenção Primária à Saúde no Brasil. Conceitos, Praticas e Pesquisa. Rio de Janeiro: Editora Fiocruz, 2018.

4- Rede Globo, RJ Cidade de 02/04/2020 entrevista com a economista Teresa Cristina Consentino, atualizada em https://oglobo.globo.com/rio/quarentena-sem-fome-acao-vai-alcancar-marca-de-20-milquentinhas-distribuidas-no-rio

5- Campanha Coletivos de Manguinhos. https://www.kickante.com.br/campanhas/solidariedade-emmanguinhos-1

6- Fase, RJ. Covid-19 escancara a injustiça da vida nas favelas e periferias. RJ, marco de 2020. Acesso in https://apublica.org/2020/04/na-ausencia-do-estado-ativistas-informam-a-periferia-sobre-ocoronavirus/

7- Fleury, S e Buss, P - Periferias e pandemia: Plano de Emergência, já! Publicado em 26/03/2020 acessado in http://www.cee.fiocruz.br/?q=pesquisa

8- Escorel, S e Arouca, L.E. Democracia e participação: para além das dicotomias. Saúde em Debate: Rio de Janeiro, v. 40, N. especial, p. 39-48, dez 2016.

9- Souza, Renata (mandata ALERJ-RJ) - Nada será como antes. Rio, 11/04/2020

10- "Mais vozes" - Direitos Humanos e a crise dos Corona vírus. (Projeto de extensão na UFPA) Live apresentada na TV GGN em 11/04/2020.

11- UOL, Noticias Vozes da Cidade, 2020/05/18 acesso https://noticias.uol.com.br/ultimasnoticias/agencia-estado/2020/05/18/contra-o-covid-19-moradores-de-paraisopolis-pedem-mais-apoiodo-governo-de-sp.htm

12- Ruiz, D. e Martufí, V. Experiencia-de-reorganizacao-da-aps-para-o-enfrentamento-da-covid-19-emSobral/CE. In https://redeaps.org.br/2020/05/25/experiencia-de-reorganizacao-da-aps-para-oenfrentamento-da-covid-19-em-sobral-interior-do-estado-do-ceara/

13- Ruiz, D. e Martufí, V. Experiencia-de-reorganizacao-da-aps-para-o-enfrentamento-da-covid-19-emFlorianopolis/SC. In https://redeaps.org.br/2020/05/21/experiencia-de-reorganizacao-da-aps-para-oenfrentamento-da-covid-19-em-florianopolis/

14- Santos, BS A cruel pedagogia do vírus. Coimbra: Editora Almedina, 2020. 